\title{
Terrorismo y acción normativa (En homenaje a Miguel Ángel Blanco Garrido)
}

\author{
MONTSERRAT BORDES SOLANAS \\ Facultat d'Humanitats \\ Universitat Pompeu Fabra
}

Todos los demócratas quisiéramos hallar una via para erradicar de una vez por todas el terrorismo que despiadadamente arranca de cuajo tantas vidas sin culpa. Si la filosofia puede ayudar en algo, aunque sólo sea realizando observaciones conceptuales y formulando argumentos libres de retórica demagógica, bienvenida sea. Más que cualquier otra, la cuestión del terrorismo necesita ser aclarada conceptualmente, con el fin de evitar la perplejidad en la que se sume la mente de algunos intachables ciudadanos cuando reflexionan, por ejemplo, acerca de la delicada frontera entre la libertad de expresión y la apología de un delito.

Las pretensiones de prescripción universal que suelen tener los análisis filosóficos sobre moralidad política, por un lado, y, por otro; la conveniencia disciplinaria de no pretender competir con políticos o con periodistas, me recomiendan eludir con frecuencia las referencias a agentes y hechos concretos, que el lector podrá fácilmente suplir con sus conocimientos del pasado y el presente históricos ${ }^{1}$.

El locus básico del ejercicio de clucidación conceptual sobre la cuestión del terrorismo puede empezar por abordar su supuesta (y esperemos que falaz) justificación por parte de quienes lo promueven. Cabe señalar que los argumentos de moralidad política contra el terrorismo lo serân también contra sus colaboradores, cuya complicidad (hospitalidad, soporte logistico, documentativo y apologético) es el sine qua non de su actividad. Señalaré también que «colaboradores» tiene aquí un sentido más amplio de lo que uno querria desear. Desde el punto de vista de la ética, que no del de la ley, los colaboradores pasivos también merecen ese nombre: lamentablemente para muchos no existe la indiferencia moral, ese cómodo estado de no compromiso ni a favor ni en contra, ya que cualquier conducta es ya un compromiso en un sentido o en otro. Su motivación (el comprensible miedo o la simple despreocupación) define ciertos matices morales, pero no exime de censura. Por supuesto que existe la suerte moral, la de quienes no han tenido que estar expuestos a una situación límite que los catalogue como héroes o villanos. A saber cuántos pusilánimes y cuántos valientes están escondidos, incluso para sí mismos, en la mullida y gris cotidianeidad, que no los pone a prueba revelảndolos a la luz pública ${ }^{2}$.

No obstante, aunque casi todos podríamos ofrecer ejemplos de la extensión del término «terrorista», en este contexto necesitamos algo más. Algunas condiciones necesarias para merecer ese calificativo parecen ser las siguientes ${ }^{3}$.

Por un lado, en el terrorista prototípico parece darse un estado de frustración ante la no realización de sus ideales políticos 4 . Dejando a un lado nuestras creencias desiderativas, el terrorista paradigmático no es egoísta, puesto que teóricamente lo sacrifica todo por su ideal, estando dispuesto a ser torturado o vejado en aras de su propósito libertador (por supuesto que no acaba de cuadrar con este perfil el que el terrorista acepte pensiones vitalicias otorgadas 
por el «Estado opresor»). Lo que distingue al terrorista de un simple delincuente es precisamente eso: que, a diferencia de las organizaciones criminales, las organizaciones terroristas operan en función de una telcología cargada políticamente. Otra cosa es que el uso de medios ilegítimos orientados a la consecución de sus ideales nos lleve acentuar asimismo su carâcter criminal $^{5}$.

En scgundo lugar, el terrorista parece operar desde la no esperanza inmediata de derrocar al gobierno que impide la realización de sus fines, así como desde la inviabilidad de un enfrentamiento bélico general. Precisamente por ello y por reconocer la necesidad del enfrentamiento, el terrorismo es vicario de la guerra convencional. Opera declarando su oposición cuasi-bélica al Estado, con un ideario impregnado del típico maniqueísmo que corresponde a los enfrentamientos de ese tipo ${ }^{6}$.

Caracterizar el terrorismo como una actividad que sc cjerce desde fuera del poder puede suscitar alguna razonable protesta por parte del lector, concretamente para quien exige un concepto de terrorismo mâs amplio, que incluya al llamado "terrorismo de Estado». Ciertamente, desde el gobierno se puede $y$ se ha ejercido una politica del terror, haciendo valer el uso tiránico de quien posee en sus manos la mayor parte de los medios represivos. Tanto si es lícito caracterizar a ese tipo de terror como terrorismo como si no, no es mi propósito, sin embargo, tratar aquí de este tipo de desviación, sino tan sólo de las acciones de ejercicio del terror que surgen desde fuera del poder establecido.

Confio en que no será para nadie una sorpresa el reconocer que estos dos rasgos mencionados no nos bastan para condenar moralmente el terrorismo ${ }^{7}$. La resistencia en los territorios ocupados por las tropas alemanas era, según estos dos rasgos, terrorista. $Y$ el terrorismo de Irlanda del Norte suele ser justificado por sus partidarios alegando que es el único medio para que la minoría católica reciba un trato ecuánime. Ahora bien, uno quisiera distinguir entre el tipo de terrorismo al que pertenece el de la resistencia frente a los nazis del terrorismo, pongamos, del que corresponde al IRA. ¿Cuál es el rasgo que convierte en indefectiblemente moral la actuación de la resistencia bajo los gobiernos nacionalsocialistas? Podemos decir, de entrada, que en virtud del grado de universalidad que exigimos a toda norma ética válida, el terrorismo moral habrá de aceptar que cualquiera debería hacer lo mismo en circunstancias semejantes y existen scrias dudas de que los terroristas a los que censuramos se hayan planteado esta cuestión, guiados como parecen estar más por un sentimiento fanático que por una límpida argumentación moral. En cualquier caso, creo que se pueden presentar al menos dos razones para discriminar evaluativamente el caso del terrorismo de la resistencia del de los terrorismos censurables ${ }^{8}$.

La primera razón es deontológica. Singer recoge en buena medida la opinión general cuando afirma que el quebrantamiento de las leyes de una sociedad democrática no es equiparable al quebrantamiento de las de una sociedad dictatorial". Efectivamente, las circunstancias sociopolíticas que rodcaban la actuación de, por ejemplo, la resistencia francesa durante la Segunda Guerra Mundial no son equiparables a las que vive hoy en día Francia, de modo que la actividad tcrorista antes y ahora no puede juzgarse como paralela. A pesar de las trampas que toda democracia, por ser humana, parece conllevar, en ella no se condenan a la clandestinidad las voces disidentes, ni se legitiman para ellas dudosos juicios sumarísimos. Para los terroristas que, en estos casos, alegan que el Estado que los alberga es realmente dictatorial o antidemocrático es fácil demostrarles que precisamente las paradojas de la democracia son las que les legitiman para poderlo decir en voz alta. Lo que 
subleva al ciudadano medio es precisamente eso, que la manzana de la democracia haya de alimentar al gusano antidemocrático que la devora, que los votos de unos cuantos legitimen a otros para favorecer la lucha contra el sistema democrático que les posibilita.su existencia. El terrorista y el proterrorista aprovechan la escrupulosa moral política del demócrata para actuar a sus anchas al margen de la ley. Sin embargo, no hemos de olvidar que, si bien la legalidad democrática y el juego electoral nos obligan a tolerar su existencia, no es menor nuestro derecho a luchar contra ellos -aunque la legal sea una vía más lenta y espinosa, finalmente ha de ser la más eficaz, tanto más cuanto que están de su parte la mayoría de los ciudadanos.

Otra razón que deslegitima al terrorismo inmoral es de carácter teleológico. Si abrazamos, como sugiero, el utilitarismo de la regla, la acción terrorista es nefasta. Según este tipo de utilitarismo, que es una especie de côctel de sabores kantianos y material utilitarista, no es moralmente válida una acción si la generalización universal de la regla o máxima pertinente que ejemplifica conllevaria consecuencias indeseables. Si todo aquel que reivindicara una causa actuara de modo terrorista, es de prever el desastre social que supondria. Lo interesante cs que el mismo principio que condena su actividad insurrecta es el que excluye pagar al terrorista con su misma moncda. Lo que excluye la «salida sucia» de la regla de oro mosaica se debe precisamente a esto: tomarse la justicia por la mano nos retrotrae a los tiempos judicialmente prehistóricos en que los tribunales desoían el más elemental habeas corpus, tiempos en los que tantos inocentes fueron condenados sin un juicio justo.

Por otra parte, aunque el utilitarismo de la regla deslegitima al terrorista, cabe decir que con mucho menos, y desde el simple consecuencialismo, se le puede deslegitimar igualmente: asesinatos masivos como el de Hipercor o el de una sola per- sona, como el del siempre recordado edil Miguel Ángel Blanco, constituyen ejemplos de las infelices consecuencias de la acción terrorista, que conllevan además el daño de desproveer a otros de sus seres queridos y generar un doliente sentimiento de indefensión en la ciudadanía, además de los daños materiales y el derroche económico que supone la precaución antiterrorista. El terrorista, sin embargo, objetará que argumentando desde el consecuencialismo su acción no es censurable ${ }^{10}$ : según él las consecuencias de su actuación han de evaluarse a largo, no a corto plazo, y la felicidad futura de la ciudadanía compensará la infelicidad presente. Aunque el pacifista no confíe en esa evaluación, parecería que nos hallamos ante el callejón sin salida de un legítimo desacuerdo evaluativo. Pero no es así. Cuando la mayoría de las gentes por cuya felicidad futura supuestamente lucha ol terrorista se manifiesta abiertamente renunciando a un futuro que sacrifique vidas inocentes, entonces, ¿qué justificación racional le queda al terrorista? La criptomesiánica posibilidad de defender que el terrorista sabe mejor que los ciudadanos cuál es la mejor manera de conseguir su felicidad social nos huele a corrupta y sórdida mentira regia.

Así que el terrorista no tendrá más remedio que singularizar sus pretensiones. Y ahî está de nuevo la falacia. El disfraz falaz del terrorista consiste en reclamar su derccho a luchar por sus propios ideales, equiparándolo al derecho que el no beligerante reclama por vivir en paz. Realmente no se trata de eso: quien argumenta contra el terrorismo sí argumenta desde la universalización de los derechos, no desde la reclamación de los suyos tan sólo, mientras que el terrorista considera tan importante su ideal como para pisotear los derechos del resto de los ciudadanos, de modo que su actuación, por no ser universalizable, es inmoral.

La normatividad de la acción humana, a saber, su condición de correcta o 
incorrecta, es algo que el filósofo en su sillón puede permitirse el lujo de problematizar. Pero el ciudadano y el político parten de ella y desearian atajar la mala hierba del terrorismo inmoral de sus cosechas democráticas.

Hubo un tiempo - y aún hay quien cree que este verbo se conjuga en presenteen que se pensaba que el diálogo era una vía para la democratización de los grupos terroristas (es decir, para su exterminación como «terroristas» y su actualización como, por ejemplo, «independentistas»). Algunos creerán que por el diálogo se pretendía convencer al terrorista de la incorreccion de sus reglas de comportamiento, de la invalidez kantiana de sus máximas de conducta ${ }^{i !}$. Pero realmente, lo que le importa al ciudadano que rechaza la acción terrorista no es la invalidez kantiana de las máximas que la guían, sino la acción como tal, sean cuales sean sus máximas conductoras. Dicho de otro modo, no es la buena o mala voluntad del terrorista lo que desea controlar el ciudadano y el político demócrata, sino la acción que resulta de ella. A diferencia de la ética que preocupa al ciudadano en casos de terrorismo, la ética kantiana pretende ir más allá del dominio de la mera conducta, regulado por la ley, en busca de la educación de la razón práctica, formándola según máximas correctas en virtud de las cuales obrar. Kant insiste en distinguir entre quien actúa correctamente «por mor del deber» y quien lo hace «meramente de acuerdo con el deber". Actúa por mor del deber quien rescata a un secuestrado por respeto a la máxima que reconoce el derecho de todos a las mismas libertades cívicas; quien, por el contrario, lo hace por cobrar una recompensa, tan sólo externamente actúa con corrección, la bondad de su acción es extrínseca a la ética. En estc sentido, las disquisiciones de Kant pueden poner en un brete tanto a los terroristas como a los defensores oficiales del orden público, algo que no entra en el debate que el ciudadano demócrata suele embastar en las conversaciones con sus contertulios habituales.

Efectivamente, cuando los políticos se sientan en la mesa de negociaciones con los representantes de los grupos terroristas, su pretensión de convicción no llega tan lejos como Kant alecciona. Eso sería pedir demasiado; erradicar la máxima inválida conllevaría, por supuesto, erradicar tambićn la acción injusta. El terrorista no sólo dejaría de atentar contra víctimas inocentes porque temiera la acción de la justicia sobre él, sino que su decisión brotaría del convencimiento de la inmoralidad misma de su actuación; creería convencidamente que su ideal no merece la sangre de vidas inocentes y no la derramaría incluso aunque supiera que no iba a ser condenado en caso contrario. El político dialogante, como decía, debe conformarse con ajustar la acción a la legalidad, aunque con ello la acción del terrorista no se acerque más a la moralidad (el terrorista puede reconducir su actuación por mero temor a la ley y a sus consecuencias, no porque haya caído por fin del caballo de la militancia insolidaria y sienta respeto por las libertades ajenas).

No obstante, y aun pidiendo menos de lo que un moralista pediría, el discurso del político dialogante nos hace pensar que pide demasiado. Parece confiar en dos cosas: (i) que es posible introyectar en el terrorista al menos una máxima general de respeto absoluto por las libertades ajenas, y (ii) que la creencia en la validez de esa máxima le conducirá a variar su actuación.

Incluso aunque el diálogo consiguiera llevar a cabo la finalidad (i), (ii) no estaría garantizada a partir de ella. No creo exagerado decir que el paso de (i) a (ii) ha sido siempre la crix, no sólo de los moralistas, sino también de los educadores, padres y legisladores de todos los tiempos. La cuestión práctica por excelencia es la de cómo conseguir que todas las justas 
reflexiones de los hombres buenos sean no sólo creídas, sino puestas en práctica. Ese maldito abismo entre lo teórico y lo práctico, entre lo que sé que debo hacer y lo que hago realmente, lo creyeron cruzar los optimistas socráticos que pensaban que entre el conocimiento moral completo y la acción justa no había más que una diferencia de milésimas de segundo. Pero el abismo es, por desgracia o por fortuna, muy grande, y el nombre académico del error en creerlo salvado es el de afalacia intclcctualista». ¿Quien dice que no haya terroristas que crean en la validez de la máxima de respeto por las libertades ajenas? No obstante, esa creencia no les impide actuar en su contra y en beneficio de los intereses de su grupo.

Ahora bien, el loable optimismo del político dialogante en su afán por propiciar un cambio en la mentalidad medios-fines del terrorista no se queda aquí: parte asimismo de un supuesto muy atrevido, a saber, que ambos comparten el conjunto suficiente de creencias de fondo como para que ese diálogo se inicie. De hecho, es más que probable que ambos se sienten a la mesa del diálogo con pretensiones opuestas: el terrorista quiere servirse del encuentro para arrancar al político dialogante ciertas concesiones para su grupo, mientras que el político quiere conseguir del terrorista el reconocimiento de que, no sólo los medios de que se sirve en su demanda son ilegítimos, sino que no puede haber concesiones sin consenso (el de los suyos con el resto de la población que está en desacuerdo con ellas y que constituye el ámbito potencial de las víctimas de su lucha armada). Todo el aspecto de un dialogo de sordos, a cuyo término los más esperanzados de los políticos deciden sacudirse el polvo de la mesa de negociaciones bajo sus pies. No en vano, como saben quienes han estado implicados en ellos, casi todos los grandes enfrentamientos históricos, por mucho que empiecen por el diálogo, siempre suelen resolverse en último término por las armas.

$Y$ es que la mentalidad del terrorista es un caso especial, mutatis mutandis, de un tipo de personalidad que nos resulta hoy en día muy sospcchosa. El conocido reto de Iván, propuesto por Dostoievsky, define esa personalidad o su opuesto: si para salvar al mundo hubieras de torturar a un niño, ¿lo harias? Casi todos los «héroes» de la historia hicieron mucho más que eso por defender su causa. En estos tiempos nuestros de antihéroes no nos plantcamos la situación tan sólo en términos éticos (si es o no legítimo sacrificar el dolor de un inocente por la liberación del resto del mundo), sino más bien en términos epistemológicos (sobre cómo puedo tener la certeza de que, en efecto, si actúo de ese modo salvaré al mundo). La repugnancia que sentimos por las guerras radica en ese escepticismo epistemológico que nos conduce al tomor espantoso de cometer un grave error moral. Después de todo, ¿valió la pena la sangre derramada del dedo de un solo ser inocente para conseguir que ondeara una bandera y no otra en los palios de los edificios oficiales? Hoy en día nos es imposible creer en la posibilidad de ver el mundo stib specie aeternitatis. Nuestros antepasados y aún demasiados hoy en día creen poder ver las cosas con el ojo de Dios, y ésa es la raíz epistemológica que alimenta el árbol del fanatismo. No sé qué dijo Kant del fanático, pero su ética no lo condena como tal: el fanático que actúe por mor del deber, según una máxima moral válida, está libre de la censura kantiana. En efecto, como afirma Hare, el fanatismo -que, junto con el nacionalismo, suele propiciar la guerra- es universalizable ${ }^{12}$. Los ideales del fanático no sólo contienen la posibilidad de la universalización, sino que la exigen (pensemos en las guerras santas, por ejemplo). Pero el fanático lleva en sí la semilla del desastre: la confianza en su infalibilidad (o cn la de la autoridad que 
reconozca, llámese «Iglesia», "partido" 0 «líder»). El fanatismo corrompe, según creo, hasta la más elevada moralidad: si la madre Teresa de Calcuta fuera realmente fanática, estaría amenazada por una soberbia que germinaría en graves errores. La flexibilidad y la comprensión de la disidencia razonada del prójimo, el término medio aristotélico, son mejores guías para la acción normativa que la intuición intelectual del filosofo rey. En este sentido podemos decir que quizá la democracia no sea el mejor de los gobiernos posibles, porque muchos que no saben opinan y deciden, pero, a falta de criterio que nos permita escoger infaliblemente a la aristocracia política (a los «mejores"), el margen de riesgo de error es inferior si muchos deciden que si unos pocos tiranos lo hacen.

Es una cuestión epistemológica la que nos lleva también a muchos a rechazar la pena de muerte, incluso para quienes vulneran en tan alto grado nuestros derechos como los terroristas. Porque la cuestión no es cómo darles lo que merecen, sino cómo saber qué merecen y quiénes son los que lo merecen. La justicia no es infalible y muchas veces los inocentes son inculpados. El reto de Dosioievsky es aquí también pertinente, dándole otro sesgo. La vida de un inoccnte no justifica el efecto disuasorio que pueda tener en los delincuentes potenciales. La medida de la cadena perpetua al menos, en el caso de que se aplique a un inocente, permite rectificar cuando se descubre el error, de modo que al menos no elimina la posibilidad de toda posibilidad, como hace la pena de muer- te ${ }^{13}$. El bíblico «no juzguéis y no seréis juzgados» da en el clavo si se lee como advertencia de que en cualquier tribunal terrenal el acusado estâ a merced de otros que posiblemente tengan una capacidad de juicio distorsionada, quizá como la suya. Pero, por supuesto, posponer la ejecución de la sentencia hasta que Ilegue la auditoria divina es algo que no nos podemos permitir los que valoramos esta vida como la mejor de todas, si no la única real. De ahí que alguna pena, si no la pena de muerte, haya de ser aplicada a quienes anteponen sus dudosos ideales a las vidas de sus victimas.

\section{BIBLIOGRAFIA}

COADY, C. A. J. (1985): "The morality of terrorism», Philosophy, núm. 60.

GeorGE, D. (1997): «Los terroristas justifican el terrorismon, Teorema, XV1/3.

HARE, R. M. (1989): Essays on political morality, Oxford, Clarendon Press.

LeTAMENDI, F. (1996): «Sobre el conflicto vasco", Revista Internacional de Filosofia Poltica, núm. 8.

LoDGE, J. (1981); Terrorism: a challenge to the State, Oxford, Robertson.

ReICH, W. (ed.) (1990): Origins of terrorism, Cambridge, Cambridge University Press.

Sincer, P. (1973): Democracy and disobedience, Oxford, Oxford University Press.

UGarte, J. (1996): «El terrorista. Alienación del héroe románticon, Leviatán, núm. 65.

\section{NOTAS}

\footnotetext{
' En nuestro país se nos ha prometido reciententente y ya en varias ocasiones el paraiso de la pasividad terrorista, pero tras un lapso de tjempo extremadamente corto en el pasado ano, la actividad etarra ha remprendido su marcha, con intensidad variable, eso
}

sí, pero también con ejecución constante. Aunque sin un alto en el camino, siempre es bueno alimentar la reflexión conceptual, aquilatada y, a la vez, precavida; porque somos conscientes, ahora como antes de que tanto nos prometieran, de que ninguna garantía nos 
asegura que los conpromisos coyunturales sean indefinidos.

2 Dejo a un lado la cuestiốn de que estrictamente, según creo y desde los hombros de Kant, ninguna luz pública puede determinar al valor moral de la voluntad de un individuo.

${ }^{3}$ Quisiera comentar al respecto que, aunque coincido parcialmente con las idcas del erisayo de Francisco Javier Ugarte, no creo que lo que of llama el $\mathrm{kjm}$ perativo terroristas siva para defintic al terrorista. El imperativo en cuestión dice: kHaz lo que yo quiero 0 asume las consecuencias» (véase la p. 16 de su «E] terrotista. Alienaciôn del léroe románticos, en Levia. tơn, núm. 65, 1996). Este imperativo es demasiado vago como para determinar una posición político-moral. Para comprobarlo baste con advertir que Ias siguientes preguntas clave no teciben respuesta definda teniéndolo en cuenta: ¿a qué tipo de consecuencias se refiere: según una ley mayoritaria o minoritaria?, ies ese yo un nosotros o un meto particular? Si las consecuencias se tarn según leyes mayoritarias y domocráticas, y si ese yo es un nosotros legal, entonces ese imperativo no puede cstạr más lejos de corresponder al que guie al terrorista.

${ }^{4}$ En el caso de los micmbros de ETA se deberia al no poder recuperar la sobcranía vasca anterior a octubre de 1839.

s Las disquisiciones acerca de la legitimidad o no de los medios utilizados en la lucha por ciertos ideales son, desde lucgo y cuando menos, controvertidas. No obstante, por lo gencral, coincidimos en que ciertas distinciones merecen ser realizadas; así, por ejemplo, sca cual sea el significado evaluativo que apliquemos a la muerte de los soldados en servicio activo en una guerra, no scrả el mismo que el correspondiente a la muerte do civiles inocentes victimas de enfrentamientos bélicos o pseudobelicos.

- Los insurgentes terroristas reproducen las características de los grupos en guerra. En palabras de Francisco Letamendi, entre ellos se dan «el maniqueismo moral, la agudización de las nociones de amizo y de enemigo, el culto a los mucrtos y la convivencia de los valores más brutales con los mâs nobles, tales como el compañerismo" ( Sobre el conflicto vascon, en Revista Internacional de Filosofia Poltitca, núm. 8, Mitirid, diciembre 1996, p. 154).

'A diferencia de la caracterización del terrorista que ofrece Lodge en las primeras páginas de su Terrorism: a chaltenge to the State, Oxford, Robertson.

* En adelante $y$ en aras de la brevedad, me referire exclusivamente al terrorismo inmoral simplemente como *terrorismon.

s Véase su Dentocracy and disobedience, Oxford, Oxford University Press, 1973.

w George en alos terroristas justifican el terrorismos (Teorema, XVI/3, 1997 ) comentu muy acertadamente que los actos terroristas suelen tener un carácter expresivo, no meramente instrumental. El terrorista puede llegar incluso a defender su actuación por razones deontológicas (!), desde la premisa de que no existen scres inocentes respecto de su lucha armada (vil. art. cit., p. 72).

"El terrorista, como otros activistas politicos, es utilitarista y, por ello, radicamente antikantiano: para el, el fin del triunfo político justifica cualquier medio para su consecucion.

12 Veanse sus Essays on political morality; Oxford, Clarendon Press, 1989. En cambio, el nacionalismo, a saber, la persecución autocéntrica del interés de un grupo individual (v. gr., del palestino, el serbio...), no es universalizable, $y$, por tanto, no es moralmente prescriptible, ya que rige en beneficio de unos cuantos seres bumanos, no de todos ellos. Notemos do paso que, aunque bastantes grupos terroristas son nacionalistas (FTA, IRA), existe nacionalismo sin terrorismo y terrorismo sin nacionalismo (GIA).

13 Los escasísimos ejemplos de reconversión espiritual entre terroristas confesos también constituyen un ámbito de referencia en este sentido. La etiologia de un proceso concreto dc reconversión del tipo al que me refiero la hallará el lector en El tazón de hierro (Barcelona, Critica, 1989), donde Fclix Novales, un militante de los GRAPO, presenta su testimonio personal, del que tuve noticias gracias a la amable sugerencia de Francisco Fernández Buey. 